\title{
As Contribuições da Formação em Bacharelado Interdisciplinar para o Processo de Escolha Profissional em Psicologia
}

\author{
Contributions of Education in the Interdisciplinary Bachelor Course to the Process \\ of Professional Choice for Psychology \\ Las contribuciones de la formación en Grado Interdisciplinario para el proceso de elección \\ profesional en Psicología
}

Marilia Neri Matos

Psicóloga, Mestre em Psicologia Social pela Universidade Federal da Bahia. Professora substituta do Centro de Ciências da Saúde da Universidade Federal do Recôncavo da Bahia.

E-mail: marilianeri@gmail.com.

\section{Mônica Lima}

Psicóloga, Doutora em Saúde Coletiva pela Universidade Federal da Bahia, Pós-doutorado em Psicologia Social pela Universidade Autónoma de Barcelona. Professora Associada I do Instituto de Psicologia da

Universidade Federal da Bahia.

E-mail: molije@hotmail.com

\section{Resumo}

Este trabalho reflete sobre as influências da formação no Bacharelado Interdisciplinar (BI) e o contato com o conhecimento psicológico, neste primeiro momento, no processo de escolha profissional. Utilizou-se a abordagem teórico-metodológica das práticas discursivas e produção de sentido. Foram entrevistados dez egressos do BI na transição para a graduação em Psicologia. Realizou-se a análise categorial temática: contribuições do BI; contato prévio com o conhecimento psicológico. Concluiu-se que o BI permitiu autonomia aos estudantes no trânsito por diferentes áreas do conhecimento. A possibilidade de acesso à matriz curricular do curso de Psicologia contribuiu para uma decisão profissional mais consistente e madura. Essa aproximação impactou na decisão sobre o percurso profissional, marcada por dúvidas que afetam não só os jovens, mas também pessoas em outro momento do ciclo vital. Este estudo permite a inclusão dos referidos aspectos para o campo da escolha profissional a partir da análise de desfamiliarização do conhecimento consolidado.

Palavras-chave: Bacharelado Interdisciplinar, Formação em Psicologia, Educação Superior.

\section{Abstract}

This work reflects on the influences of education in the Interdisciplinary Bachelor course (IB) and the contact with the psychological knowledge, in this first moment, for the process of professional choice. The theoretical-methodological approach of discursive practices and production of meaning was applied. Ten graduates of IB were interviewed at their transition to Psychology undergraduate course. An analysis by thematic category was carried out: IB contributions; previous contact with psychological knowledge. It was concluded that IB provided autonomy to the students so they could transit through different areas of knowledge. The possibility to access the study programme of the Psychology course contributed to a more consistent and mature professional decision. This approach influenced the career decision, which is characterized by uncertainties that affect not only young people, but also those who are later in life cycle. This study enables the inclusion of these aspects for the field of professional choice, based on the analysis of de-familiarization of consolidated knowledge.

Keywords: Interdisciplinary Bachelor Course, Psychology Education, Higher Education. 
Resumen

Este trabajo reflexiona sobre las influencias de la formación en el Grado Interdisciplinario (GI) y el contacto con el conocimiento psicológico, en este primer momento, en el proceso de elección profesional. Se utilizó el enfoque teórico y metodológico de las prácticas discursivas y producción de sentido. Entrevistamos a 10 estudiantes egresados de GI en la transición para la carrera en Psicología. Se llevó a cabo el análisis categorial temático: las contribuciones del GI; el contacto previo con el conocimiento psicológico. Se concluyó que el GI permite la autonomía de los estudiantes en la circulación por diferentes áreas del conocimiento. La posibilidad de acceder al plan de estudios de la carrera de Psicología contribuyó a una decisión profesional más consistente y madura. Este enfoque impactó en la decisión sobre la trayectoria profesional, marcada por dudas que afectan no sólo a los jóvenes, sino también a la gente en otro momento del ciclo vital. Este estudio permite la inclusión de estos aspectos para el campo de la elección profesional a partir del análisis de desfamiliarización de los conocimientos consolidados.

Palabras-clave: Grado interdisciplinario, Formación en Psicología, Educación Superior.

Este artigo é fruto da dissertação de mestrado intitulada "A formação em Bacharelado Interdisciplinar e suas contribuições na escolha profissional em Psicologia". Neste texto, discutimos o impacto e a importância da vivência no Bacharelado Interdisciplinar para a formação em Psicologia como aspectos significativos para o processo de escolha profissional nesse campo de atuação.

Atualmente, a universidade brasileira experiencia um cenário de questionamentos e mudanças sobre o seu papel institucional. Uma das indagações gravita em torno da escolha precoce do estudante sobre sua carreira profissional comumente realizada no Ensino Médio (Santos \& Almeida-Filho, 2008), sem que, em muitos casos, haja contato prévio e conhecimentos básicos consistentes sobre a profissão. Cabe destacar que a realidade universitária atual promoveu políticas de acesso ao Ensino Superior a uma parte generosa da população cujas famílias não possuem tradição familiar universitária, posto que alguns estudantes são os primeiros de sua família a acessar esse nível de ensino (Instituto de Pesquisa Econômica Aplicada, 2010).

A entrada na universidade envolve a escolha do curso de interesse do estudante, permitindo o seu desenvolvimento em várias dimensões, consolidando suas habilidades para a atuação profissional, dependendo também dos objetivos das instituições de ensino. Essa escolha está atrelada ao seu projeto de futuro e, por isso, se apresenta como um momento de grande significado, comumente ocorrendo em uma fase do ciclo vital bastante delicada, a adolescência (Filomeno, 2005).

A escolha profissional é um marco temporal do percurso de vida de um sujeito, é inquestionável a relevância desse momento decisório na vida das pessoas (Nepomuceno \& Witter, 2010). Por ser uma escolha complexa, ela não deve ser vista como um fato isolado, mas sim como um processo dialético multideterminado que interfere na trajetória do sujeito (Bock \& Aguiar, 1995). Fatores familiares, sociais, políticos, econômicos, educacionais e psicológicos marcam essa decisão e não devem ser desconsiderados (Soares, 2002).

Entretanto, essas contribuições sobre escolha profissional abordam as questões da decisão na fase da adolescência, em sua maioria, idealizando um perfil único de adolescente, considerandoos como um grupo homogêneo, sem considerar múltiplas faces, por exemplo, as questões sociais e os grupos de adolescentes de classes populares (Teixeira, 2011). Apesar do processo de escolha profissional culminar, para uma grande parcela da população, com o fim do Ensino Médio e a continuidade dos estudos, devemos destacar que a escolha profissional também é um desafio para pessoas em diferentes fases do ciclo vital, muitas que já possuem um percurso profissional e se inserem ou se reinserem no universo acadêmico. A partir do levantamento de produções bibliográficas, não foram encontrados estudos 
que abarcassem esses públicos, o que denota uma lacuna no estudo das temáticas da escolha profissional. Além deles, os grupos de pessoas sem tradição familiar universitária também precisam ser analisados, contribuindo para o desenvolvimento de conhecimentos mais amplos sobre a escolha profissional, principalmente, as mudanças decorrentes na ultima década de políticas mais inclusivas no Ensino Superior.

Ao optar por uma profissão, o sujeito se insere em um contexto novo, de construção de novos conhecimentos e formação da sua identidade profissional, repleto de medos, desafios e curiosidades. Em relação ao desenvolvimento dessa identidade, o fator educacional, atrelado à estrutura do Ensino Superior e aos investimentos do governo nele, influi não apenas na escolha, mas na trajetória que o estudante vivencia após o início de uma formação (Filomeno, 2005).

As características estruturais e de investimento governamental no Ensino Superior são alvo de mudanças quando, em 2008, todas as Universidades Federais do Brasil aderem ao Programa de apoio aos planos de expansão e reestruturação das Universidades Federais (REUNI). Esta ação promoveu a implantação, entre outros incentivos, dos Bacharelados Interdisciplinares (BIs), reconfigurando a formação universitária para além de contextos profissionalizantes. A proposta de um olhar interdisciplinar dessa modalidade de ensino, especificamente na UFBA, busca oferecer uma visão ampla, crítica e atual aos estudantes, ampliando o saber, criando novos conhecimentos e redefinindo o ensino na universidade (UFBA, 2008).

De modo geral, os BIs se delineiam como o primeiro dos ciclos da formação universitária, voltado para uma formação que acompanha a complexidade e a diversidade cultural do mundo contemporâneo (Ministério da Educação, 2010). Na mesma direção, Mazoni, Custódio, e Sampaio (2011) esclarecem que o BI, na UFBA, se mostra como uma nova possibilidade de formação universitária, contrária à escolha profissional precoce dos estudantes do Ensino Médio, bem como um modelo que questiona os contextos de graduação atuais focados na profissionalização prematura e especializada.
Na UFBA, as mudanças se estabeleceram como um "semirregime de ciclos", uma vez que a universidade não adotou radicalmente a proposta de formação em ciclos (Lima, Coutinho, Jalil, \& Lopez, 2016), no sentido de manter entrada única pelos BI para todos os estudantes novos, conservando a entrada diretamente para os cursos de progressão linear (CPL), além da transição dos egressos do BI para os CPLs, após três anos, no mínimo de formação interdisciplinar. Além disso, os BI foram implantados em quatro grandes áreas, sendo elas Saúde, Humanidades, Ciência \& Tecnologia e Artes. Outro aspecto do projeto, e que merece destaque, é a previsão de áreas de concentração. Estas permitem que o estudante construa um perfil acadêmico e/ou ocupacional, com disciplinas e atividades importantes para o aprofundamento em determinados campos de saberes e práticas (UFBA, 2008).

Nessa perspectiva, acredita-se que, ao concluir o BI, o sujeito estará apto a ingressar em cursos de progressão linear (CPL) ou em formação acadêmica de pós-graduação ou ainda no mundo do trabalho em ocupações que não exijam formação profissional específica (UFBA, 2008).

Essa reformulação na arquitetura da universidade tem suscitado pesquisas e análises sobre as repercussões e os resultados dos BIs, bem como dos seus desdobramentos (Lima, Coutinho, Almeida-Filho, \& Sampaio, 2012; Mazoni et al., 2011; Teixeira, Coelho, \& Rocha, 2013), adicionando conhecimento a uma experiência nova e em franco desenvolvimento visto que, até o presente momento, os BIs já foram implantados em nove das 54 Universidades Federais do país (Ministério da Educação, 2010) e, por ser uma inovação na realidade educacional brasileira, estudos sobre a criação, implantação e a realidade dos BIs se mostram imprescindíveis.

$\mathrm{O}$ BI visa permitir a problematização do processo de escolha profissional a partir de uma vertente complementar daquela já clássica no campo, permitindo que o estudante entre em contato com as áreas de conhecimento na vivência da formação geral, agregando saberes sobre tais áreas sem precisar escolher por uma área 
especifica. Assim, ao cursar o BI de Humanidades, por exemplo, o estudante poderá conhecer diversos campos da área, bem como cursar componentes curriculares de Psicologia e de qualquer outro curso existente sem estar restrito a um único curso e/ou a uma única área de conhecimento. Nessa direção, buscamos discutir se a estratégia permite a possibilidade de definir um futuro profissional com maior embasamento.

Diante do exposto, esse artigo buscou refletir sobre a influência da formação interdisciplinar dos estudantes no BI a partir do contato com componentes curriculares previstos para a graduação em Psicologia e demais cursos no processo de escolha profissional.

O texto foi organizado em três partes. A primeira abordou os aspectos teórico-metodológicos adotados, inspirados na perspectiva do construcionismo social, particularmente, na vertente da produção de sentidoe as práticas discursivas (Spink, 2000). Em seguida, em resultados e discussão, buscamos discutir os sentidos das trajetórias acadêmicas dos estudantes do BI que transitaram para o CPL de Psicologia, utilizando a análise categorial temática (Vazquez, 1996). Nesta comunicação, refletimos sobre duas categorias envolvidas no processo de escolha profissional entre os entrevistados: (1) as contribuições do BI ou da formação interdisciplinar e (2) contato prévio com o conhecimento exigido na formação em Psicologia, problematizando possíveis contribuições do BI para o cenário universitário. Podemos perceber que o BI influenciou na tomada de decisão, fundamentou o poder decisório dos estudantes, por permitir o contato paulatino e sistemático com diferentes áreas de conhecimento e com a própria Psicologia. Por fim, como considerações finais, destacamos que a formação interdisciplinar aporta no processo de tomada de decisão profissional, tornando-a mais madura e consciente.

\section{Método}

Este estudo foi realizado com base em uma pesquisa exploratória, de caráter descritivo, utilizando o método qualitativo. Além disso, foi inspirado nos pressupostos teórico-metodológicos do movimento construcionista em Psicologia Social (Gergen \& Gergen, 2010), na vertente da Psicologia Discursiva (Spink, 2000), que entende como ciência uma forma de construir sentidos sobre os eventos do mundo, como uma prática social como todas as demais.

A pesquisa construcionista social convida o pesquisador a sair do local habitual, compreendendo o contexto em que os fenômenos foram desenvolvidos e analisando o seu efeito, acatando uma postura ética no desenvolvimento do conhecimento, bem como assumindo um compromisso histórico para compreender os conteúdos como construções históricas e culturalmente localizadas (Spink, 2010). A adoção de uma postura mais abrangente permite a desfamiliarização, proposta por Spink (2000), como um movimento de análise de construções conceituais já estabelecidas que se transformam em crenças, ampliando a compreensão sobre o que é estudado.

Entre as construções sociais, segundo Spink (2000), está o sentido que se define como uma construção social através da qual as pessoas, inseridas em um determinado contexto sócio-histórico, compreendem e significam os fenômenos. A produção de sentido acompanha a vida humana e não se dá de forma individualizada, mas se constrói como uma prática que tem a linguagem como base. É através da linguagem que se criam os sentidos que constroem e significam os fenômenos do mundo. Além disso, essa linguagem pode ser importante na compreensão do poder de discursos expressados por diferentes contextos de saber (Spink, 2010).

As práticas discursivas, por sua vez, são constituídas por uma variedade de produções sociais que levam ao entendimento da produção de sentido cotidiano. Esta pode ser entendida como a "linguagem em ação", já que é por intermédio 
dessas práticas que as pessoas produzem sentidos e se posicionam socialmente em relação a eventos cotidianos. As atribuições do participante sobre o fenômeno permitem que os significados sejam explorados nos seus contextos. Ao mesmo tempo, o pesquisador participa da produção de sentidos e a entrevista se mostra como uma interação dialógica, despertando construções, análises e possibilidades (Spink, 2000).

\section{Participantes}

Os participantes da presente pesquisa foram estudantes egressos do Bacharelado Interdisciplinar de uma Universidade Federal brasileira, que fizeram a transição para o curso de Progressão Linear de Psicologia (CPL-Psi) em 2013. Após contato e concordância com a participação, eles foram entrevistados individualmente e identificados com nomes fictícios para garantir o sigilo, assegurando o compromisso ético da pesquisa.

Alguns aspectos podem ser destacados a partir dos dados sociodemográficos por idade (Tabela 1). A maioria dos entrevistados era do sexo feminino e possuía mais de 30 anos. Como o gênero feminino prevalece entre os participantes, optamos por relatar e discutir os dados a partir desde gênero. Entre essas, quatro eram casadas, a maioria com filhos e com uma história de inserção tardia ou reinserção no universo universitário, como será mais bem discutido a seguir. Notamos que as entrevistadas contemplavam um perfil heterogêneo de estudantes, não se reduzindo a jovens, solteiras e sem filhos.

Em relação à formação anterior ao ingresso na UFBA, conhecimento prévio sobre a Psicologia por pertença à tradição familiar universitária, podemos destacar alguns aspectos (Tabela 2). Apenas quatro estudantes jovens ingressaram no BI após conclusão imediata do Ensino Médio, seguindo o percurso que se tem considerado comum entre as jovens brasileiras. Por sua vez, cinco entrevistadas (com ou sem graduação prévia), ingressaram após inserção anterior no mundo do trabalho. Uma estudante ingressou no BI após concluir Letras e não estava satisfeita com o referido curso. No entanto, ressaltamos que havia pessoas com graduação prévia reingressando na universidade para fazer um curso não profissionalizante. Por sua vez, chamou atenção que a maioria das entrevistadas venha de família com tradição familiar universitária, mas que também haja aqueles que pertenciam a famílias cujos pais não fizeram universidade. Por outro lado, cabe frisar que, entre aquelas

Tabela 1

Dados sociodemográficos por idade

\begin{tabular}{lcccc}
\hline Identificação & Sexo & Idade & Estado Civil & Filhos \\
\hline Abaixo dos 30 anos & & & Solteiro & 0 \\
Paulo & Masculino & 23 & Solteiro & 0 \\
Henrique & Masculino & 25 & Solteira & 0 \\
Alice & Feminino & 23 & Solteira & 0 \\
Sofia & Feminino & 21 & & Filhos \\
Acima dos 30 anos & & & Estado Civil & 1 \\
Identificação & Sexo & Casada & 0 \\
Maria & Feminino & 40 & Solteira & 2 \\
Carla & Feminino & 32 & Casada & 0 \\
Ana & Feminino & 54 & Solteira & 0 \\
Bianca & Feminino & 34 & Casada & 3 \\
Lorena & Feminino & 45 & Divorciada \\
Marta & Feminino & 44 & & \\
\hline
\end{tabular}

Fonte: Dados coletados nas entrevistas (2015). 
Tabela 2

Formação anterior ao ingresso na UFBA, conhecimento prévio sobre a Psicologia por pertença à tradição familiar universitária

\begin{tabular}{lccc}
\hline Identificação & $\begin{array}{c}\text { Formação } \\
\text { Anterior }\end{array}$ & $\begin{array}{c}\text { Ensino } \\
\text { Médio }\end{array}$ & $\begin{array}{c}\text { Conhecimento prévio } \\
\text { da Psicologia }\end{array}$ \\
\hline Sem Tradição Familiar Universitária & Nível técnico & Público & Não \\
Maria & Ensino Médio & Público & Não \\
Paulo & Graduada em Teologia & Público & Sim \\
Lorena & Nível técnico & Público & Não \\
Marta & & & \\
Com Tradição Familiar Universitária & Ensino Médio & Particular & Não \\
Henrique & Graduada em Direito & Particular & Sim \\
Carla & Graduada em Geografia & Público & Sim \\
Ana & Ensino Médio & Não Informado & Sim \\
Alice & Ensino Médio & Particular & Sim \\
Sofia & Graduada em Letras & Público & Sim \\
Bianca & & & \\
\hline
\end{tabular}

Fonte: Dados coletados nas entrevistas (2015).

que pertenciam a famílias com tradição familiar universitária, estiveram os que sinalizaram algum conhecimento sobre a Psicologia. E entre as que não tinham tradição familiar universitária, apenas aquela que já fez um curso superior.

Em relação ao histórico escolar no Ensino Superior, destacamos que todas das entrevistadas fizeram a área de concentração Estudos da Subjetividade e do Comportamento Humano (AC$\mathrm{ESCH}$ ). O fato de ter participado dessa área de concentração significa que as estudantes tiveram acesso a componentes curriculares do campo da Psicologia durante sua formação interdisciplinar no BI. A AC-ESCH pretende conferir às estudantes um domínio de conhecimentos, de caráter não-profissional, concernentes ao campo da Psicologia. Nessa direção, a estudante do BI pode ter acesso aos componentes curriculares (CCs) da matriz do CPL-Psico em torno de $35 \%$, exceto aos CCs profissionalizantes (por exemplo, Avaliação Psicológica, Psicoterapia, entre outros) tendo oportunidade de conhecer esse campo de conhecimento mais diretamente, ainda durante sua formação no BI (Lima, Coutinho, \& Santos, 2015). Neste estudo, as autoras iniciam a discussão sobre a perspectiva do acesso aos CCs possibilitar uma escolha profissional mais consistente e madura.

\section{Instrumento}

Para a coleta de dados, após a aplicação do Termo de Consentimento Livre e Esclarecido, foi utilizada a entrevista semiestruturada, explorando as temáticas da escolha profissional, abarcando os sentidos que cada uma das participantes construiu sobre os temas em pauta e de que forma tais sentidos influenciam nessa experiência. Durante as entrevistas, foi realizada uma exploração das experiências concretas vividas direta ou indiretamente pelas participantes, solicitando que as descrevessem e que refletissem em relação à qualidade que atribuíam à formação universitária no BI.

\section{Procedimentos de análise de dados}

Em relação aos procedimentos de análise de dados, as entrevistas foram transcritas e submetidas a uma análise de discurso categorial temática (Vazquez, 1996). Essa análise de discurso foi realizada em alguns procedimentos. Inicialmente, lemos muitas vezes as entrevistas na íntegra para reativar a memória e fixar cada uma das trajetórias analisadas. Depois, fizemos a decomposição do texto em unidades e as 
agrupamos por categorias seguindo o critério da analogia. Partimos dos objetivos da investigação, considerando as semelhanças entre essas unidades, as identificando e agrupando em categorias (Vasquez, 1996).

Nessa abordagem, a análise foi realizada a partir de três etapas consecutivas e recursivas: pré-análise, codificação e categorização (Vasquez, 1996). Na pré-análise, foi realizada a organização do material que seria analisado com base nos objetivos da investigação e da análise. Durante a codificação, foi realizada uma análise buscando transformar os dados brutos (material original) em dados úteis (resultado das análises em função dos objetivos estabelecidos). Para a transformação, o texto foi fragmentado em unidades de registro, um trecho do conteúdo com significação, e ocorreu uma catalogação dos elementos baseados em sua presença, analisando a importância desses em relação aos objetivos. Por fim, na categorização ocorreu a organização das unidades obtidas a fim de encontrar uma visão condensada dos dados trabalhados. Abaixo, destacamos, então, as categorias, definições e códigos elaborados na análise dos discursos das entrevistadas sobre a sua trajetória acadêmica e transição do BI para o CLP-Psicologia (Tabela 3).

Tabela 3

Temática e categorias de análise do estudo

\begin{tabular}{lll}
\hline $\begin{array}{l}\text { Escolha profissional } \\
\text { Categoria }\end{array}$ & Descrição & Código \\
\hline O BI como contribuição para a escolha & $\begin{array}{l}\text { A experiência do BI como possível contribuição para } \\
\text { a decisão por uma escolha profissional; o contato } \\
\text { com a Psicologia como área de conhecimento e } \\
\text { profissão durante o BI, e através da AC-ESCH. }\end{array}$ & BIEP \\
$\begin{array}{l}\text { Contato prévio com a Psicologia como con- } \\
\text { tribuição para a escolha profissional. }\end{array}$ & $\begin{array}{l}\text { O conhecimento ou contato com a área ou com } \\
\text { profissionais que podem ter contribuído para } \\
\text { essa escolha antes da entrada no BI. }\end{array}$ & CONT \\
\hline
\end{tabular}

Fonte: Dados coletados nas entrevistas (2015).

\section{Resultados e discussão}

\section{O BI como contribuição para a escolha profissional}

A pesquisa realizada por Lima, Coutinho, Almeida-Filho, \& Sampaio (2016), com a primeira turma de egressos do BI que migrou para o CPL de Psicologia, concluiu que algumas entrevistadas identificaram o BI como uma oportunidade de realizar uma escolha mais segura e consciente, a partir do contato prévio com as diferentes áreas do conhecimento e com a Psicologia especificamente. Essas entrevistadas consideravam o BI como um espaço de conhecimento e de experiência, dentro do contexto universitário, de uma etapa preliminar para a escolha profissional, amadurecendo a experiência acadêmica para posterior tomada de decisão sobre essa alternativa profissional.
Os discursos das nossas entrevistadas animam a mesma construção social da primeira turma de egressos do BI em relação ao papel dessa formação no processo de escolha profissional:

Será que ali, esse BI não é uma oportunidade de você ir experimentando um pouco, você decidir se é aquilo que você quer? (...) Acho que é uma possibilidade de você passar pelos institutos, passar pela estrutura, né? (...) E passear por vários lugares. Isso eu acho que é fundamental. (A., BIEP, comunicação pessoal, 17 de novembro, 2015).

Porque, por exemplo, eu tinha feito vestibular 
pra universidade particular pra Psicologia $[\mathrm{Na}$ mesma época do BI]. Mas, também tinha feito o vestibular pra Fisioterapia. Então, eu não sabia muito bem o que eu queria. Então, o fato de eu ter experienciado no BI essas diversas áreas me fez também perceber o que eu realmente queria, né? Onde eu queria me implicar. (P., BIEP, comunicação pessoal, 06 de agosto, 2015).

Os exemplos de discursos das duas entrevistadas, que também aparecem nas trajetórias de outras participantes deste estudo, reafirmam a influência do BI como uma oportunidade de amadurecer ou definir a escolha profissional. Vale ressaltar que a estrutura curricular do BI permite também que o estudante se insira em uma pós-graduação ou uma licenciatura, para além de um curso profissionalizante.

Como explanado por Paulo, a indecisão sobre a escolha profissional foi uma experiência vivenciada por ele, que se inscreveu em diferentes vestibulares, e o BI teve um papel importante para que ele experimentasse os diferentes campos de conhecimento e então definir o seu percurso na Psicologia.

O BI atraiu um público heterogêneo com diferentes perfis e interesses, além de idades bem diversas (Mazoni, et al. 2011; Sampaio, Barbosa, Santos, Fernandes, \& Dantas, 2013). A influência nessa escolha profissional, como apontado por Ana, não esteve presente apenas na trajetória das estudantes recém-saídas do Ensino Médio, mas também com pessoas adultas com experiências e trajetórias acadêmicas e/ou profissionais prévias. A experiência do BI também foi destacada por Maria:

Então, eu peguei várias optativas lá em cima de Psicanálise, várias. E aí eu ficava maravilhada. Feliz. Cada aula melhor do que outra. Cada professora! E eu via que eu tinha que avançar. (...) E eu agradeço ao BI, porque se não fosse o BI eu não teria conhecido porque, como eu já te disse, minha família não teve essas informações todas que é muito natural para algumas pessoas. Muita gente demora de chegar. (M., BIEP, comunicação pessoal, 04 de julho, 2015).

O projeto pedagógico do BI (UFBA, 2008), ao discutir o modelo tradicional de ensino brasileiro, indica a necessidade de superar alguns efeitos negativos da decisão precoce sobre o percurso profissional. Como ocorre com alguns estudantes ao término do Ensino Médio, a decisão da carreira a seguir é tomada de forma precoce (Teles, 2015; Vieira, 2015), não só pela idade cronológica em si, mas pela falta de informação consistente sobre as profissões e o mundo do trabalho (Vieira, 2015). A partir do discurso das entrevistadas, podemos considerar que o conhecimento que elas tinham sobre as profissões foi adquirido por intermédio de palestras em escolas, como apontado por Henrique, ou publicações que traziam algumas informações básicas sobre as carreiras, assim como ocorreu com Marta, além de meios de comunicações, a internet, professores e outras pessoas significativas. O que nos permitiu questionar se esse conhecimento por si só é suficiente para essa decisão.

O BI apresenta um cenário novo em relação à escolha profissional quando insere essa decisão na universidade, uma escolha que antes era realizada do lado de fora do universo acadêmico (Vieira, 2015). Por isso, uma proposta de formação geral que permita uma maior flexibilidade ao estudante se coloca como uma importante ferramenta na tomada de decisão sobre a profissão ou mesmo sobre os seus interesses acadêmicos ou em ocupações futuras sem enquadre profissionalizante.

O discurso de Maria também traz uma reflexão sobre os processos de escolha profissional e suas influências quando as estudantes não possuem uma tradição familiar universitária consolidada. Atualmente, o acesso mais intensificado desse grupo populacional ocorre com a adoção de políticas educacionais afirmativas (IPEA, 2010). Sabemos que o Ensino Superior, no Brasil, é colocado como uma possibilidade de ascensão social (Sampaio et al., 2013) e consequente melhoria da qualidade de vida das pessoas. Essa busca por melhorias e o desenvolvimento de 
acesso a um maior número de estudantes com as ações afirmativas e de permanência permitiram que pessoas sem tradição familiar universitária ingressassem no universo acadêmico.

Eu entrei querendo Direito. Aí depois eu comecei pegando algumas matérias, comecei a ler alguns livros, e aí começou air se despertando em mim... Tinha uma dúvida já. Mainha ainda falava assim: "É, por que você não pega essa matéria Introdução à Psicologia pra você ver como é mais ou menos e tal?". Aí eu fiz: tá. Peguei. Aí quando eu peguei fui gostando porque [o componente curricular] Introdução à Psicologia dá um geral do que é a psicologia. Aí depois eu peguei Psicologia e os Problemas Sociais, Sexualidade, Subjetividade e Cultura ${ }^{1}$, ai eu fiz: é, acho que é esse caminho aqui. (S., BIEP, comunicação pessoal, 18 de abril, 2014).

O discurso de Sofia aborda o papel do BI na escolha profissional de forma curiosa. A estudante ingressou no BI com o intuito de continuar sua formação no CPL de Direito, entretanto, à medida que experienciou os componentes concernentes à Psicologia, percebeu o despertar de um novo interesse. A estudante se encontrava em dúvida sobre as definições do seu percurso profissional, porém a possibilidade proporcionada pelo BI no trânsito em diferentes áreas de conhecimento, podendo inclusive ampliar o conhecimento em uma área de concentração (AC), permitiu que ela definisse a sua decisão. A influência dos pais, como apontado pelos estudos (Filomeno, 2005; Nepomuceno \& Witter, 2010; Vieira, 2015) é importante no processo de escolha profissional. A sugestão da mãe de Sofia auxiliou no amadurecimento da sua decisão posterior pelo CPL. A novidade é que o BI proporciona isso, porque tem uma matriz curricular mais flexível do que os demais cursos do CPL.

A possibilidade de cursar áreas de concentração (AC) no BI também pode ser analisada como incidindo no processo de escolha profissional. A proposta da AC é se apresentar como um conjunto de estudos teóricos e práticos com coerência e que auxiliem no desenvolvimento de um perfil profissional e/ou acadêmico. Essa não tem como função apenas antecipar o contato das estudantes com estudos iniciais da área de conhecimento, mas sim aprofundar o conhecimento em campos de saberes e práticas (UFBA, 2008). No grupo de participantes do presente estudo, analisando os históricos escolares das entrevistadas na universidade em questão (Tabela 3), percebemos que todas as estudantes que transitaram para o CPL-Psi optaram por realizar a área de concentração Estudos da Subjetividade e do Comportamento Humano (AC-ESCH), de responsabilidade do Instituto de Psicologia.

Pelos discursos de Sofia e Maria percebemos também que a vivência da $A C$ pode contribuir na escolha profissional à medida que o estudante não se engesse em uma área de conhecimento, permitindo que essa área não incida de forma demasiada na formação interdisciplinar. Como explanado no projeto pedagógico (UFBA, 2008), a AC busca aprofundar o conhecimento, mas não restringir o estudante em uma área especifica. Como afirmam Lima et al. (2016) sobre a AC-ESCH, os estudantes podem escolher os componentes curriculares do seu interesse, compondo suas trajetórias individuais e singulares.

Independentemente das influências e dos motivos pelos quais as estudantes entrevistadas optam pela continuidade dos estudos no CPL de Psicologia, é notável que a experiência do BI, ao possibilitar acesso ao espaço universitário e às áreas de conhecimento, bem como o contato prévio com a Psicologia, auxiliam na tomada de decisão sobre a profissão. Essa escolha parece se tornar mais fortalecida à medida que esses estudantes se inserem no espaço universitário e entram em contato com as temáticas da Psicologia a partir dos componentes curriculares ofertados para as estudantes dos BIs. Essa é uma possibilidade

1 Esses componentes curriculares são oferecidos pelo IPS/UFBA aos BIs, e fazem parte da matriz curricular do curso de Psicologia. Nos casos citados, são CCs optativos. 
que enriquece a trajetória acadêmico/profissional independentemente de o estudante optar por seguir o CPL de Psicologia e, como destacam Lima et al. (2016), a instituição estudada é a única universidade no país a possibilitar o acesso progressivo e sistemático dos estudantes universitários aos conteúdos da Psicologia como área de conhecimento e profissão, sem que eles estejam matriculados no curso de Psicologia.

\section{Contato prévio com a Psicologia como contribuição para a escolha profissional}

Uma das possíveis influências para a escolha profissional é o contato prévio que os estudantes têm com a Psicologia antes do ingresso na universidade. Os conteúdos verbalizados por Alice demonstram que essa influência pode ser um fator importante na decisão pela Psicologia. Alice afirma que já possuía o interesse em cursar a Psicologia antes da entrada no BI, mas por ela e sua mãe, figura citada em diversas passagens da entrevista, terem sabido do projeto do BI e se interessado pela proposta, ela decidiu iniciar ali o seu percurso acadêmico-profissional.

Eu sempre gostei, assim, de observar o outro, me interessava pelo mundo interno das pessoas e tal. Minha mãe é terapeuta, também, então essa coisa na minha casa, sempre se conversou o tempo inteiro sobre esses processos psicológicos, eu tenho uma tia que é psicóloga (...) então tive bastante aproximação antes de escolher.... (A., CONT, comunicação pessoal, 10 de abril, 2014).

A influência dos pais é apontada por diversos estudos (Bohoslavsky, 1977/1998; Filomeno, 2005; Nepomuceno\& Witter, 2010; Vieira, 2015) como preponderantes no processo de escolha profissional. As figuras de referência são importantes para a reflexão sobre o tipo de profissional que a pessoa deseja ser baseandose no desempenho dos adultos (Bohoslansky, 1977/1998).

Para Henrique, o contato prévio ocorreu com um professor em uma palestra proporcionada pela escola. Porém, essa não é considerada para ele, uma experiência com caráter decisório.

Pra Psicologia, eu lembrei aqui agora que no colégio tinha essas rodadas de profissões... Tinha os profissionais que falavam sobre as profissões e tudo o mais... E se eu não me engano, eu tenho quase certeza que era um professor aqui da UFBA que foi falar lá. (...) $E$ dentre essas opções, que tava voltada à Área 3, Psicologia era uma. (...) Foi meio, quase um sorteio. (Risos) Quase um sorteio. (H., CONT, comunicação pessoal, 06 de agosto, 2015).

Os fatores de influência para a escolha de uma profissão podem ser dos mais variados. O estudante que não conta com uma maior proximidade com a profissão, no caso a Psicologia, conhece apenas superficialmente as atribuições do profissional, elencando, como foi relatado por Henrique, critérios que não garantem uma escolha consciente. Essa escolha foi amadurecendo a partir da sua trajetória dentro do BI de Humanidades e da experiência prévia em Psicologia em uma faculdade particular. O contato com a Psicologia foi o diferencial no fortalecimento dessa escolha, demonstrando que o acesso às suas temáticas e seus docentes auxilia na tomada de decisão mais consciente.

As estudantes sem tradição familiar universitária apresentaram características diferenciadas em relação às entrevistadas com essa herança. Com exceção de Lorena, que se aproximou da Psicologia por um interesse desde a adolescência, e por meio de um curso em que estabeleceu contato com diferentes psicólogas, as outras três entrevistadas não tiveram contatos prévios com a profissão, apesar de, como relataram Maria e Marta, possuírem sua própria visão sobre a Psicologia. Maria relatou uma visão estereotipada de psicóloga como "médico de louco". Segundo Leme, Bussabe, e Otta (1989), uma imagem comum da sociedade em geral em relação a essa classe profissional. Podemos considerar que ainda existe esse tipo de imaginário sobre o campo de atuação da Psicologia. 
Não tinham [tradição familiar universitária] e Psicologia, pra mim, era: só procura quem é maluco. O lugar que eu morava, né, um bairro simples, humilde, as pessoas que procuravam psicólogo era porque, hoje que eu sei, né, era porque surtou, desencadeou um surto... E precisou ir pro "Juliano" [refere-se ao Manicômio Juliano Moreira], e Psicologia existia no meu universo nesse contexto. (M., BIEP, comunicação pessoal, 04 de julho, 2015).

Marta, por sua vez, relata um perfil de proximidade com as questões da subjetividade humana e, mesmo que não veja o BI como uma influência para sua escolha profissional, nem esteja certa de que irá atuar na Psicologia, se reconhece nessa área de conhecimento.

Eu sempre tive um... como eu sempre tive uma facilidade muito grande de aproximação com as pessoas, eu sempre uso essa marca que eu sou uma pessoa facilitadora na relação. Talvez isso para mim seja uma característica, não que todo psicólogo tenha, mas, digamos, que isso facilita muito a relação do psicólogo. Então. Eu acho que é uma coisa que me cai bem. Eu diria assim: "É uma roupa que me cai bem". (M., CONT, comunicação pessoal, 01 de dezembro, 2015).

Marta revela que a escolha inicial pela Pedagogia foi uma opção que lhe pareceu adequada, considerando o seu momento no ciclo vital, por ser uma mulher com mais de trinta anos, com três filhas e um neto. A Pedagogia lhe pareceu um espaço em que seria aceita e teria facilidade em se inserir profissionalmente. A vivência do BI, apesar de não ter influenciado na escolha pela Psicologia, foi determinante para a revisão das influências dessas escolhas pela Pedagogia e pela opção por cursar o BI, que lhe pareceu mais atrativo do que o currículo rígido e pré-determinado de um curso linear em uma turma composta, em sua grande maioria, por jovens abaixo dos vinte anos, como relatou.
A partir dos resultados apresentados, podemos perceber que a proximidade com a área de conhecimento auxilia o estudante no processo de tomada de decisão sobre o seu percurso profissional. Esse contato pode ser proporcionado pelo BI sem que o estudante tenha que decidir por uma área única de conhecimento, conhecendo algumas delas e optando de forma mais consciente sobre a sua formação acadêmica e profissional.

Assim, podemos identificar, a partir dos dados apresentados, que as dúvidas relacionadas a essa decisão profissional não afetam apenas os adolescentes recém-saídos do Ensino Médio, mas também um público adulto que, muitas vezes, por não ter uma tradição familiar universitária, ou por não possuir um contato prévio com as profissões, não está seguro das suas escolhas. Essas percepções permitem problematizar a relação estabelecida entre a escolha profissional e a adolescência, segundo a qual se acredita que essa decisão é afetada pelo momento do ciclo vital em que essas pessoas se encontram, a transição da infância para a adolescência, e de alterações físicas, psíquicas e comportamentais que geram conflitos e desafios por si sós.

Tal percepção alerta para a necessidade de estudos sobre orientação profissional que não se foquem apenas no público adolescente. Os estudos sobre a escolha profissional e a Psicologia, como atuante na orientação profissional, devem analisar esse público com um perfil heterogêneo, com histórias prévias e também indecisões sobre o futuro. Sinalizamos que, ao não serem incluídos em estudos, essas pessoas parecem invisíveis no contexto universitário, como se todas as pessoas da sociedade, mesmo as de classes sociais desfavorecidas que têm acesso ao Ensino Superior incentivados por programas instituídos pelo governo, ingressassem no Ensino Superior ao fim do Ensino Médio.

Além disso, destacamos a relevância de estudos sobre a escolha profissional e o BI, problematizando as temáticas sobre essa decisão, a vivência do espaço universitário e do contato com as áreas de conhecimento. Por ser uma novidade, o BI se mostra como terreno fecundo para a Psicologia 
pensar, construir e revisar suas ideias e conceitos sobre a escolha profissional e a orientação profissional/vocacional realizada classicamente. Muitas questões podem surgir do encontro entre a Psicologia e os Bacharelados Interdisciplinares, mas sinalizamos que uma lacuna nesse campo é a investigação desses novos estudantes, desse público heterogêneo que escolhe o $\mathrm{BI}$ e, como foi objeto de análise nesse estudo, define a Psicologia como profissão possível.

Uma das contribuições identificadas a partir dos discursos das entrevistadas sobre a experiência no BI foi que seguir uma área de concentração (AC) pode contribuir no processo de escolha profissional, assegurando que essa área não seja uma influência preponderante que inviabilize a formação interdisciplinar, mas que permita uma trajetória mais fluida do estudante entre as áreas de conhecimento com foco em algum campo, sem se engessar em uma única área do conhecimento.

O contato prévio com os conteúdos atrelados à Psicologia, como ressaltam Lima e Coutinho (prelo) tem democratizado institucionalmente o acesso ao conhecimento psicológico antes da graduação em Psicologia. Como ressaltam as autoras, essa proposta de contato prévio com as áreas de conhecimento também incide na criação de uma função socioinstitucional para uma escolha profissional crítica e consistentemente orientada.
A abordagem teórico-metodológica do presente estudo permitiu o olhar sobre os sentidos construídos pelas estudantes como produções desenvolvidas dentro de uma sociedade específica e em um determinado momento da história, possibilitando que o contexto fosse considerado, analisando os discursos das entrevistadas não como verdades inquestionáveis, mas sim como construções constituídas por uma variedade de ideias que emergem das interações sociais.

Além disso, a desfamiliarização (Spink, 2000) proporcionou uma análise da educação superior a partir de suas crenças e suas construções sociais, desfamiliarizando e desnaturalizando o modelo tradicional de ensino, não considerando o modelo já instituído como uma verdade fixa. Ao propormos analisar a educação superior, o BI e a Psicologia, estamos possibilitando a criação de espaços de coexistência entre o tradicional e o novo, entre o disciplinar e o interdisciplinar, ressignificando os moldes de educação a partir de uma atualização sócio-histórica. Mais particularmente, introduzindo um elemento novo para o campo da escolha profissional e orientação profissional/vocacional, permitindo que com a desfamiliarização do conhecimento consolidado se produzam reflexões para o aperfeiçoamento desse campo de estudo e de intervenção.

\section{Referências}

Bock, A. M. B., \& Aguiar, W. M. J. (1995). Por uma prática promotora de saúde em Orientação Vocacional. In A. M. B. Bock (Ed.), Amaral, C. M. M.; Silva, F. F.; Silva, L. B. C.; Calejon, L. M. C.; Lehman, Y. P. (Orgs.). A Escolha Profissional em Questão (pp. 9-24). São Paulo: Casa do Psicólogo.

Bohoslavsky, R. (1977/1998). Orientação vocacional: a estratégia clínica. São Paulo: Martins Fontes.

Lima, M., Coutinho, D., Jalil, C. M., \& Lopez, F. N. (2016). Transição dos Bacharelados Interdisciplinares para a Formação em Psicologia. Psicologia: Ciência e Profissão, 36(1), 183-195. doi: 10.1590/1982-3703002042013

Coulon, A. (2008). A condição de estudante: a entrada na vida universitária. Salvador: Edufba.

Filomeno, K. (2005). Mitos familiares e escolha profissional: uma visão sistêmica. São Paulo: Vetor.
Gergen, K. J., \& Gergen, M. (2010). Construcionismo social: um convite ao diálogo. Rio de Janeiro: Instituto Inoos.

Instituto De Pesquisa Econômica Aplicada (IPEA). (2010). Estudo comparado sobre a Juventude Brasileira e Chinesa - Dados preliminares do Brasil. Relatório de pesquisa. Brasília: IPEA; SBS. Recuperado de http:// www.ipea.gov.br/portal/index.php?option=com content\&view=article\&id $=15948$

Leme, M. A. V. D. S., Bussab, V. S. R., \& Otta, E. (1989). A representação social da Psicologia e do Psicólogo. Psicologia: Ciência e Profissão, 9(1), 29-35. doi: 10.1590/ S1414-98931989000100009

Lima, M., Coutinho, D., Almeida-Filho, N., \& Sampaio, S. (2012). Trajetórias acadêmicas e construção de significados e sentidos na transição dos Bacharelados Interdisciplinares à formação em Psicologia na UFBA. Projeto de Pesquisa. Programa pense, pesquise e inove a UFBA. 
Lima, M., Coutinho, D., \& Santos, V. (2015). Trajetórias interrompidas no curso de Psicologia em relação ao Bacharelado Interdisciplinar na Ufba. Camine: Caminhos da Educação, 7(2), 30-51. Recuperado de https://ojs. franca.unesp.br/index.php/caminhos/article/view/1364

Lima, M. \& Coutinho, D. (prelo). Percepções de egressos do Bacharelado Interdisciplinar no curso de Psicologia da Ufba. Estudos Interdisciplinares em Psicologia, Londrina.

Mazoni, I., Custódio, L., \& Sampaio, S. (2011). Bacharelado interdisciplinar da Universidade Federal da Bahia: O que dizem os estudantes? In S. Sampaio (Ed.), Observatório da vida estudantil: primeiros estudos (p. 273). Salvador: Edufba.

Ministério da Educação. (2010). Referenciais Orientadores para os Bacharelados Interdisciplinares e Similares. Brasília: MEC.

Nepomuceno, R. F., \& Witter, G. P. (2010). Influência da família na decisão profissional: opinião de adolescentes. Psicologia Escolar e Educacional, 14(1), 15-22.doi: 10.1590/S1413-85572010000100002

Sampaio, S. M. R., Barbosa, J. S., Santos, I. D., Fernandes, N., \& Dantas, M. (2013). Nova Universidade, novos estudantes: quem são e o que esperam os estudantes dos bacharelados interdisciplinares da Universidade Federal da Bahia. In S. M. R. Sampaio \& G. G. Santos (Eds.), Observatório da vida estudantil: universidade, responsabilidade social e juventude (p. 388). Salvador: Edufba.

Santos, B. S., \& Almeida-Filho, N. (2008). A Universidade no sec. XXI: por uma universidade nova. Coimbra: Almedina.

Soares, D. H. L. (2002). A escolha profissional: do jovem ao adulto. São Paulo: Sumus.
Spink, M. (2000). Práticas discursivas e produções de sentido no cotidiano: Aproximações teóricas e metodológicas. Rio de Janeiro: Cortez.

Spink, M. (2010). Linguagem e produção de sentido no cotidiano. Rio de Janeiro: Edelslein. doi: 10.7476/9788579820465

Teixeira, A. M. F. (2011). Entre a escola pública e a universidade: longa travessia para jovens de origem popular. In S. M. R. Sampaio (Ed.), Observatório da vida estudantil: primeiros estudos (pp. 27-51). Salvador: Edufba.

Teixeira, C. F. D. S., Coelho, M. T. Á. D., \& Rocha, M. N. D. (2013). Bacharelado interdisciplinar: Uma proposta inovadora na educação superior em saúde no Brasil. Ciencia \& Saude Coletiva, 18(6), 1635-1646. doi: 10.1590/ S1413-81232013000600015

Teles, M. V. A. O. (2015). Os Bacharelados Interdisciplinares na UFBA: Percepções discentes sobre currículo e formação. Salvador: Dissertação de Mestrado. Universidade Federal da Bahia.

Universidade Federal da Bahia (2008). Projeto Pedagógico dos Bacharelados Interdisciplinares. Salvador, 2008. Recuperado de https://www.ufba.br/sites/devportal. ufba.br/files/implant_reuni.pdf

Vázquez, F. (1996). El análisis de contenido temático. Objetivos y medios en la investigación psicosocial. (Documento de trabajo) (pp. 47-70). Universitat Autònoma de Barcelona.

Vieira, C. M. B. (2015). Os fatores predominantes na escolha pelos cursos de Bacharelado Interdisciplinar da UFBA. (Dissertação de Mestrado). Universidade Federal da Bahia: Salvador. Recuperado de http://www.repositorio. ufba.br:8080/ri/handle/ri/18208 